\title{
COMMENTARY
}

\section{Mechanical ventilation and intra-abdominal hypertension: 'Beyond Good and Evil'}

\author{
Paolo Pelosi* and Maria Vargas \\ See related research by Regli et al., http://ccforum.com/content/16/5/R208/abstract
}

\begin{abstract}
Intra-abdominal hypertension is frequent in surgical and medical critically ill patients. Intra-abdominal hypertension has a serious impact on the function of respiratory as well as peripheral organs. In the presence of alveolar capillary damage, which occurs in acute respiratory distress syndrome (ARDS), intra-abdominal hypertension promotes lung injury as well as edema, impedes the pulmonary lymphatic drainage, and increases intra-thoracic pressures, leading to atelectasis, airway closure, and deterioration of respiratory mechanics and gas exchange. The optimal setting of mechanical ventilation and its impact on respiratory function and hemodynamics in ARDS associated with intra-abdominal hypertension are far from being assessed. We suggest that the optimal ventilator management of patients with ARDS and intraabdominal hypertension would include the following: (a) intra-abdominal, esophageal pressure, and hemodynamic monitoring; (b) ventilation setting with protective tidal volume, recruitment maneuver, and level of positive end-expiratory pressure set according to the 'best' compliance of the respiratory system or the lung; (c) deep sedation with or without neuromuscular paralysis in severe ARDS; and (d) open abdomen in selected patients with severe abdominal compartment syndrome.
\end{abstract}

Those who fight monsters should take care not to become a monster himself. And if you look into an abyss, the abyss will look into you.

- 'Beyond Good and Evil: Prelude to a Philosophy of the Future', Friedrich Nietzsche

*Correspondence: ppelosi@hotmail.com

Department of Surgical Sciences and Integrated Diagnostics, University of Genoa, L.go R. Benzi, 8 - 16132 Genoa, Italy
The study by Regli and colleagues [1] in the previous issue of Critical Care reports the effects of different levels of positive end-expiratory pressure (PEEP) on respiratory function and hemodynamics in an animal model of acute respiratory distress syndrome (ARDS) associated with intra-abdominal hypertension (IAH). IAH is highly prevalent in critically ill patients and has a serious impact on the function of the lungs and peripheral organs [2]. In the presence of alveolar capillary membrane damage, IAH promotes lung injury [3] as well as edema and increases intra-thoracic pressures, leading to atelectasis, airway closure, and deterioration of gas exchange [4].

Regli and colleagues [1] reported an increase of endexpiratory lung volume and gas exchange, with a reduction of pulmonary shunt and dead space fraction when intra-abdominal pressure (IAP)-matching PEEP was applied. Although high IAP-matching PEEP decreased cardiac output, moderate IAP-matching PEEP provided a compromise between lung function and hemodynamics. In an experimental model of IAH in normal animals, the same authors showed that PEEP level matched to IAP did not improve oxygenation but reduced cardiac output [5].

The optimal setting of mechanical ventilation in ARDS with IAH has not been assessed yet. As a consequence, the hemodynamics and respiratory effects of mechanical ventilation in these patients cannot be predicted.

A protective ventilation strategy with a low tidal volume (6 $\mathrm{mL} / \mathrm{kg}$ ideal body weight) and an airway plateau pressure of below $30 \mathrm{~cm} \mathrm{H}_{2} \mathrm{O}$ improves survival in patients with ARDS [6]. On the other hand, low tidal volume may lead to alveolar de-recruitment in the presence of ARDS associated with IAH. The effect of tidal volume in IAH depends on the degree of inspiratory trans-pulmonary pressure that is usually reduced because of cephalic shift of the diaphragm. Recently, Santos and colleagues [3] showed that, in extra-pulmonary ARDS with $\mathrm{IAH}$, high tidal volume $(10 \mathrm{~mL} / \mathrm{kg}$ ideal body weight) decreased atelectasis and inflammatory response of the lung tissue and improved oxygenation by increasing end-inspiratory trans-pulmonary pressure.

Recruitment maneuvers in patients with ARDS may have a beneficial effect on the respiratory function [7]. In 
the presence of IAH and increased chest wall elastance, the inspiratory pressure of the respiratory system applied during recruitment maneuver should be higher than usually applied, in order to achieve an inspiratory transpulmonary pressure that is large enough enough to reopen collapsed alveoli.

The study by Regli and colleagues [1] shows that the PEEP setting based simply on IAP could have a negative impact on hemodynamics. Previous clinical studies reported different results on the role of PEEP in ARDS patients with IAH. Krebs and colleagues [8] showed similar beneficial effects of PEEP on gas exchange and alveolar recruitment in ARDS patients with or without IAH. Gattinoni and colleagues [9] showed that the effects of PEEP on alveolar recruitment were more beneficial in patients with extra-pulmonary as compared with pulmonary ARDS. However, independently of IAH, both studies found that the 'optimal' PEEP should be selected according to the 'best' elastance of the respiratory system and the lung. Higher PEEP in the presence of IAH markedly increases pleural pressure, negatively affecting cardiovascular function [10] and impeding the lymphatic drainage [11]. It is likely that, in cases in which higher PEEP levels are required, the open abdomen might be considered, according to patient's clinical condition [12]. The prophylactic use of the open abdomen technique should be reserved for surgical patients with a high risk of abdominal compartment syndrome and death [13].

In patients with severe ARDS and IAH, the prone position could be used to reduce the cranial diaphragmatic load [14], even if prone positioning may induce a mild elevation in IAP or ameliorate or exacerbate IAH [15] and may be difficult to apply in patients with transiently open abdomen treatment. Finally, experimental evidence suggests that assisted ventilation should be cautiously applied in the presence of mild or severe ARDS associated with IAH [12].

In conclusion, we suggest that the optimal ventilator management of patients with ARDS and IAH would include the following: (a) intra-abdominal, esophageal pressure, and hemodynamic monitoring; (b) ventilation setting with protective tidal volume, recruitment maneuvers, and PEEP level set according to the 'best' compliance of the respiratory system or the lung; (c) deep sedation with or without neuromuscular paralysis in severe ARDS; and (d) open abdomen in selected patients with severe abdominal compartment syndrome.

\section{Abbreviations}

ARDS, acute respiratory distress syndrome; IAH, intra-abdominal hypertension; IAP, intra-abdominal pressure; PEEP, positive end-expiratory pressure.
Competing interests

The authors declare that they have no competing interests.

Published: 18 December 2012

\section{References}

1. Regli A, Mahendran R, Fysh ET, Roberts B, Noffsinger B, De Keulenar BL, Singh $B$, Van Heerden PV: Matching positive end-expiratory pressure to intraabdominal pressure improves oxygenation in a porcine sick lung model of intra-abdominal pressure. Crit Care 2012, 16:R208.

2. Malbrain ML, Chiumello D, Pelosi P, Bihari D, Innes R, Ranieri VM, Del Turco M, Wilmer A, Brienza N, Malcangi V, Cohen J, Japiassu A, De Keulenaer BL, Daelemans R, Jacquet L, Laterre PF, Frank G, de Souza P, Cesana B, Gattinoni L: Incidence and prognosis of intraabdominal hypertension in a mixed population of critically ill patients: a multiple-center epidemiological study. Crit Care Med 2005, 33:315-322.

3. Santos CL, Moraes L, Santos RS, Oliveira MG, Silva JD, Maron-Gutierrez T, Ornellas DS, Morales MM, Capelozzi VL, Jamel N, Pelosi P, Rocco PR, Garcia CS: Effects of different tidal volume in pulmonary and extrapulmonary lung injury with or without intrabdominal hypertension. Intensive Care Med 2012, 38:499-508.

4. Quintel M, Pelosi P, Caironi P, Meinhardt JP, Luecke T, Herrmann P, Taccone P, Rylander C, Valenza F, Carlesso E, Gattinoni L: An increase of abdominal pressure increases pulmonary edema in oleic acid-induced lung injury. Am J Respir Crit Care Med 2004, 169:534-541.

5. Regli A, Chakera J, De Keulenaer BL, Roberts B, Noffsinger B, Singh B, Van Heerden PV: Matching positive end-expiratory pressure to intra-abdominal pressure prevents end-expiratory lung volume decline in a pig model of intra-abdominal pressure. Crit Care Med 2012, 40:1879-1886.

6. Putensen C, Theuerkauf N, Zinserling J, Wrigge H, Pelosi P: Meta-analysis: ventilation strategies and outcomes of the acute respiratory distress syndrome and acute lung injury. Ann Intern Med 2009, 151:566-576.

7. Pelosi P, Gama de Abreu M, Rocco PR: New and conventional strategies for lung recruitment in acute respiratory distress syndrome. Crit Care 2010, $14: 210$.

8. Krebs J, Pelosi P, Tsagogiorgas C, Zoeller L, Rocco PM, Yard B, Luecke T: Open lung approach associated with high-frequency oscillatory or low tidal volume mechanical ventilation improves respiratory function and minimizes lung injury in healthy and injured rats. Crit Care 2010, 14:183.

9. Gattinoni L, Pelosi P, Suter PM, Pedoto A, Vercesi P, Lissoni A: Acute respiratory distress syndrome caused by pulmonary and extrapulmonary disease. Different syndromes? Am J Respir Crit Care Med 1998, 158:3-11.

10. Staffieri F, Stripoli T, De Monte V, Crovace A, Sacchi M, De Michele M, Terragni PP, Ranieri VM, Grasso S: Physiological effects of an open lung ventilator strategy titrated on elastance-derived end-expiratory transpulmonary pressure: study in a pig model. Crit Care Med 2012, 7:2124-2131.

11. Hederstierna G, Lattuada M: Lymphatic and lymph in acute lung injury. Curr Opin Crit Care 2008, 14:31-36.

12. Pelosi P, Luecke T, Rocco PR: Chest wall mechanics and abdominal pressure during general anaesthesia in normal and obese individuals and in acute lung injury. Curr Opin Crit Care 2011, 7:72-79.

13. Mentula $P$, Leppaniemi A: Prophylactic open abdomen in patients with postoperative intra-abdominal hypertension. Crit Care 2010, 14:111-113.

14. Abroug F, Ouanes-Besbes L, Dachraoui F, Brochard L: An updated study-level meta-analysis of randomized controlled trials on proning in ARDS and acute lung injury. Crit Care 2011, 15:R6.

15. Kirkpatrick AW, Pelosi P, De Waele JJ, Malbrain ML, Ball CG, Meade MO, Stelfox $H T$, Laupland KB: Clinical review: intra-abdominal hypertension: does it influence the physiology of prone ventilation? Crit Care 2010, 14:232-243.

doi:10.1186/cc11874

Cite this article as: Pelosi P, Vargas M: Mechanical ventilation and intra-

abdominal hypertension: 'Beyond Good and Evil'. Critical Care 2012, 16:187. 